\title{
APOIO FAMILIAR NO APORTE FINANCEIRO PARA NOVOS NE- GÓCIOS RESULTANTES DE PROJETOS EDUCACIONAIS
}

\author{
FAMILY SUPPORT IN THE FINANCIAL CONTRIBUTION TO NEW BUSINESS STEMMING \\ FROM EDUCATIONAL PROJECT
}

\begin{abstract}
Luiz Diego Vidal Santos
Mestre em Ciências da Propriedade Intelectual pela Universidade Federal de Sergipe - UFS. Atualmente é fiscal do Conselho Regional de Educação Física e estagiário pesquisa da Universidade Federal de Sergipe - UFS. São

Cristóvão, SE - Brasil.

vidal.center@academico.ufs.br

Francisco Sandro Rodrigues Holanda

Pós-Doutor pela Universidade de Wisconsin (EUA). Atualmente é professor Titular da Universidade Federal de Sergipe - UFS, Coordenador do Laboratório de Erosão e Sedimentação - LABES e líder do Grupo de Pesquisa em Gestão Hidroambiental do Baixo São Francisco. São Cristóvão, SE - Brasil. fholanda@infornet.com.br

Rayssa Juliane Souza Santos Graduanda de Engenharia Florestal pela Universidade Federal de Sergipe - UFS. São Cristóvão, SE - Brasil. rayssajs@icloud.com
\end{abstract}

\begin{abstract}
Resumo: Esta pesquisa tem por objetivo verificar a influência do apoio familiar no aporte financeiro aos projetos de negócios resultante de grupos de estudantes participantes do Programa de extensão Empreenda Agro Sustentável. Este estudo caracterizase como Survey descritivo exploratório, conduzido no período de desenvolvimento do programa educacional que ocorreu de agosto a novembro de 2019, recorrendo à análise das duas dimensões, a intenção/pretensão em empreender dos estudantes e a participação familiar e influência de terceiros no desenvolvimento do empreendedorismo. Pode-se perceber que os alunos participantes apresentam forte necessidade de apoio financeiro vindo de outras esferas tais como linhas de créditos e apoio de investidores. Por meio dos resultados obtidos nesta pesquisa ficou evidente que, os alunos envolvidos no decorrer do programa demostraram que mesmo adquirindo conhecimento e capacidade de evolução dos negócios desenvolvidos, necessitam de apoio externo ao seu círculo de convivência para pôr a frente o empreendimento.
\end{abstract}

Palavras-chave: Negócios familiares. Startups. Sustentabilidade. Projeto de Extensão.

Abstract: This research aims to verify the influence of family support on the financial contribution to business projects resulting from groups of students participating in the Empreenda Agro Sustentável extension program. This study is characterized as an exploratory descriptive survey, conducted in the period of development of the educational program that took place from August to November 2019, using the analysis of the two dimensions, the intention / intention to undertake the students and the family participation and influence of third parties. in the development of entrepreneurship. It can be seen that the participating students have a strong need for financial support from other spheres such as credit lines and support from investors. Through the results obtained in this research, it was evident that the students involved in the course of the program demonstrated that even acquiring knowledge and capacity to evolve the developed businesses, they need external support to their circle of coexistence to put the enterprise forward.

Keywords: Family business. Startups. Sustainability. Extension Project.

Para citar - ABNT NBR 6023:2018

SANTOS, Luiz Diego Vidal; HOLANDA, Francisco Sandro Rodrigues; SANTOS, Rayssa Juliane Souza. Apoio familiar no aporte financeiro para novos negócios resultantes de projetos educacionais. Cadernos de Pós-graduação, São Paulo, v. 19, n. 2, p. 234-252, jul./dez. 2020. Disponível em: https://doi.org/10.5585/cpg.v19n2.18378. 


\section{Introdução}

Acredita-se que o mercado de trabalho para os novos profissionais atuantes nas áreas das ciências agrárias tem mudado, pois a busca pela valorização das capacidades e competências ocupacionais tem crescido substancialmente, tais como: a afirmação e promoção de direitos de cidadania, associatividade política, responsabilidade social e ambiental, consideração, respeito às diversidades étnicas e culturais. Desta forma, os futuros profissionais do meio rural devem acompanhar esta tendência mercadológica do desenvolvimento rural de forma sustentável (LAZZARESCHI, 2016). Para tal, o ambiente acadêmico tem um papel importante neste contexto, que é o de fomentar e oportunizar tais competências.

Com as universidades e institutos de educação superior sendo reconhecidamente contextualizados como promotores da educação e inovação no Brasil, este novo paradigma educacional, portanto, situa as instituições de ensino no campo da promoção das competências necessárias para lidar com as mudanças de consumo e necessidade profissional. A universidade vem a ser um local privilegiado do saber, da liberdade acadêmica e da experimentação científica, conseguindo 'oficializar' o ensino como conteúdo de conhecimento e uma ferramenta capaz de gerar novos comportamentos (ANDRADE; FERNANDES, 2016). Muito tem se estudado sobre quais ferramentas podem influenciar nas demandas de competências individuais que atualmente são buscadas pelo mercado de trabalho rural, uma delas é a educação em empreendedorismo (SCHAEFER; MINELLO, 2017).

A educação em empreendedorismo disciplinada atualmente mostra-se eficaz no que diz respeito ao surgimento das novas competências profissionais direcionadas, a promoção de inovação e para soluções de problemas em negócios rurais (COSTA et al., 2018). Estudos têm mostrado que ela é capaz de capacitar profissionais adaptados às novas demandas e agregar valor ao capital humano das empresas. Segundo Dornelas (2015), o empreendedorismo significa fazer algo novo, diferente, mudar a situação atual e buscar, de forma incessante, novas possibilidades de negociações, tendo como foco a inovação e a criação de valor. Leite e Dias (2015), trata o empreendedorismo como um processo, que se concentra em iniciar e gerir empreendimentos, isto é, o conjunto de conceitos, métodos, instrumentos e práticas relacionadas com a criação, implantação e gerenciamento de novas empresas ou organizações. O desenvolvimento sustentável compreendido como um negócio socialmente responsável e ecologicamente correto, mas invariavelmente viável em termos financeiros necessita de um profissional capaz de lidar com todas as invariabilidades do campo (LOPES, 2010; FAUSTINO; AMADOR, 2016). 
Atualmente estes tipos de negócios contribuem para o crescimento de diversas regiões geográficas, uma vez que não se expandem apenas em tamanho, como também novos locais, além de incentivar ocupações laborais em suas indústrias relacionadas. Supletivamente, como muitas dessas microempresas são responsáveis por desenvolver novas tecnologias e processos, elas também geram aumento de absorção do capital humano mais capacitado para gerenciamento empresarial (VICENTINI; PIZZUTTI; CARVALHO, 2018).

No contexto metodológico educacional capaz de influenciar no aprendizado, temos as metodologias ativas, que trazem a possibilidade de mudança da centralidade no docente para o estudante, ponto de vista preconizado por Freire (1987) ao abordar educação como um processo que não é realizado por outrem, ou pelo próprio indivíduo, mas que acontece na interação entre pessoas através de sua vivência por palavras, ações e reflexões. Sucintamente, as metodologias ativas propõem transformar o processo de aprendizagem na busca pelo comportamento empreendedor, como uma forma de enfrentar o modelo tradicional praticado e aceito ao longo dos anos.

Tal conceito define o empreendedorismo como uma prática constante das atividades rotineiras dos educandos. Nesse contexto, deve existir uma maior produção de estudos e conteúdos sobre o empreendedorismo, e os modelos educacionais que melhor se apliquem ao aprendizado deste, como ressalta Ferreira et al. (2017). O indivíduo empreendedor é o ator qualificado a inovar no processo evolutivo do mundo contemporâneo, capacitado para resolver problemas e absorver oportunidades, atribuindo-se este sujeito como causa da mudança, e capaz de lidar com as constantes inversões do mercado econômico (SCHAEFER; MINELLO, 2017). No Brasil, existe uma progressiva necessidade da educação ao empreendedorismo correto e escalável, um país que segue um constante crescimento de empregos informais (IBGE, 2020).

O Brasil apresentou um contingente de pessoas que só conseguiram trabalho no período 2012 a 2019 na condição de informalidade, tipo laboral que atingiu um recorde da série histórica iniciada em 2012, e chegando em 2019 a, 41,4\% de recursos humanos ocupados informalmente (NITAHARA, 2019). Foi também registrada uma taxa crescente de dispensa de trabalhadores nas idades iniciais de empregabilidade - 18 a 24 anos - desde 2012 , dados obtidos na Pesquisa Nacional por Amostra de Domicílios Contínua (PNAD Contínua) (NITAHARA, 2019).

Mesmo que os alunos graduados ainda apresentem lacunas de formação em seu potencial empreendedor, cabe às universidades criar processos de ensino e aprendizagem que preencham esses espaços. Buscando atender às demandas atuais dos negócios rurais, se faz necessário compreender melhor o empreendedorismo desenvolvido que mantenha a sustentabilidade em áreas rurais, como também a aplicação das práticas sustentáveis no meio rural (PIETROVSKI et al., 2019). 
Torna-se imprescindível destacar que o desenvolvimento sustentável no meio rural não pode ter suas bases de compreensão apenas no progresso econômico local ou regional, é necessário, então, ter um olhar sistêmico que permeie todo o processo ocorrido no campo, e que envolva outras dimensões, como por exemplo a sociocultural, a político-institucional e a dimensão ambiental (VIEIRA; BERNARDO; LOURENZANI, 2015). O desenvolvimento rural sustentável é de certa forma fruto do desenvolvimento social, pois, nasce da compreensão que o campo é um ambiente que depende da circularidade de produtos para manter-se existente (PIRAUX; CANIELLO, 2019). No Brasil, o desenvolvimento rural teve início com as políticas de "Intensificação verde", ações conhecidas como revolução verde, plano político que teve força de ação nos anos 60 (KAGEYAMA, 1990).

Tal desenvolvimento teve como ponto positivo o estreitamento das fronteiras entre o meio rural e o meio urbano, tornando-as cada vez mais tênues e difusas (FREITAS; FREITAS; DIAS, 2012), uma vez que a sociedade civil emerge como protagonista do processo de construção dos pilares para um desenvolvimento mais responsável e abrangente (SOUZA et al., 2016). Essa compreensão se firma quando a produção no campo se posiciona ao introduzir inovações anti-predatórias, tendo como base a economia circular e ao tornar mais densas as redes de cooperação, buscando a autossuficiência consciente, e satisfazendo as necessidades atuais, sem comprometer a capacidade das gerações futuras de suprir suas próprias necessidades (BASTOS; MATTOS; SANTOS, 2018).

A inovação, a propagação da inovação e o surgimento de novos empreendimentos são considerados, em muitos países, importantes sinais para o crescimento e recuperação de crises econômicas (SILVA, 2017), que estão ligados diretamente ao desenvolvimento intelectual do capital humano. O Investimento no capital humano desde a formação acadêmica permite também o surgimento de melhorias no ambiente de labor e rotina, assim como aumenta os níveis de produtividade e renda dos futuros profissionais (BASTOS; MATTOS; SANTOS, 2018).

Parece, deste modo, interessante investigar a figura do aluno como sujeito potencialmente empreendedor, uma pessoa capaz de identificar oportunidades, criar negócios, e reunir os recursos necessários face aos riscos e incertezas (PIETROVSKI et al., 2019), não somente um limitado autômato solucionador de problemas. No início dos anos 80 o empreendedorismo estava diretamente ligado ao desenvolvimento econômico e à criação de postos de trabalho em um país (RODRIGUES et al., 2019), passando a ser visto como importante fator a ser explorado nas comunidades acadêmicas.

Atualmente, ao pensar em tecnologias inovadoras para o campo, é necessário compreender as necessidades do público consumidor, o meio urbano, como também as possíveis capacidades de 
atendimento do meio rural às demandas, de maneira que, as trocas comerciais não afetem a autossustentabilidade do campo e todas as características ambientais, sociais e culturais. Assim, este trabalho analisa a influência do apoio familiar no aporte financeiro aos projetos de negócios resultante de grupos de estudantes participantes do Programa de Extensão Empreenda Agro Sustentável.

\section{Materiais e métodos}

Esta pesquisa está focada na dissonância entre a teoria e prática dos métodos educacionais e nas mudanças vertiginosas do mercado de trabalho no meio rural. Este setor foi escolhido por estar contribuindo significativamente para a balança comercial do país, apresentando saldos positivos frequentes, e igualmente contribui para a segurança alimentar e produção de produtos limpos e renováveis (BRASIL, 2020).

Visando compreender a influência da participação familiar e influência de terceiros no desenvolvimento do empreendedorismo de negócios rurais resultantes de programa de extensão universitária para os alunos dos cursos do Centro Ciências Agrárias Aplicadas (CCAA) da Universidade Federal de Sergipe (UFS), foi escolhida a população para esta pesquisa de 1227 discentes dos cursos de graduação em Engenharia Agronômica, Engenharia Agrícola, Zootecnia, Engenharia Florestal, Medicina Veterinária e Engenharia de Pesca. Estes dados estão presentes no relatório estatístico de matrículas de 2017 da instituição (UNIVERSIDADE FEDERAL DE SERGIPE, 2018).

A amostra desta pesquisa compreende 118 discentes que participaram do programa Empreenda Agro Sustentável. As atividades foram desenvolvidas por meio de quatro workshops (oficinas de aprendizagem) orientados por metodologias ativas, palestras tendo em conta a promoção da aprendizagem significativa e colaborativa.

Durante os módulos do projeto (workshops), os participantes testaram seus insights para que novas requisições fossem realizadas e/ou que erros nos planejamentos fossem encontrados e, consequentemente, debatidos e mitigados. Depois que todas as Sprints (atividades dos três workshops) foram finalizadas, ou seja, que todos os módulos foram abordados, foi iniciado um ciclo de apresentações e desenvolvimento da habilidade de apresentação e demonstração dos produtos em apresentações sumárias (pitchs). O programa foi desenvolvido em quatro encontros "workshops", que abordaram temas pertinentes ao empreendedorismo e ao comportamento empreendedor, a saber: 


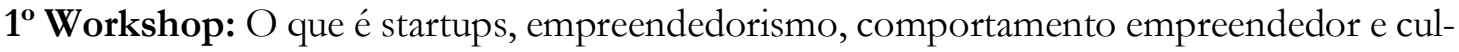
tura empreendedora e problemas (segmentação do mercado), segundo os Objetivos do Desenvolvimento Sustentável (ODS); Modelagem do negócio e Criatividade;

$2^{\mathbf{0}}$ Workshop: A busca de oportunidades como característica empreendedora, construção do Lean Canvas, mapa de empatia, validação da proposta de valor, economia colaborativa e Coworking;

$3^{\mathbf{o}}$ Workshop: (Hackathon): Prototipagem para o MCVP (Mínimo Produto Comercialmente Viável); O que você pode fazer por seu cliente e como o cliente adquire seu produto?;

$4^{\text {o }}$ Workshop: (Demoday): O Demoday ou Dia de Demonstração dos modelos de negócios das startups foi realizado no dia 22 de novembro de 2019. Esse foi o evento em que as startups se apresentaram para investidores, que são representados por venture capitals, aceleradoras ou investidores anjos. Nessa oportunidade os jovens empreendedores apresentaram seus projetos em busca de investimentos.

As startups formadas pelo programa realizaram a exposição e apresentação de seus modelos de negócio e protótipos, bem como a apresentação dos pitchs de cada equipe para o público presente que buscou cada bancada, além de participação em um "Talk Show" com mais uma exibição de pitchs para todo público presente no evento.

\section{Survey aplicado}

O estudo caracteriza-se como uma pesquisa de levantamento ou Survey, que se destaca por compreender uma amostra expressiva em relação ao universo pesquisado. Para isso foi utilizado como parâmetro de ferramenta avaliativa, o modelo de survey Global University Entrepreneurial Spirit Students Survey, conhecido nacionalmente por estudo GUESSS.

Esta ferramenta de ensaio acadêmico que busca caracterizar o espírito, as atividades e as intenções empreendedoras de estudantes universitários, de todos os níveis de aprendizagem e em todos os cursos universitários, bem como as condições de ensino e apoio a atividades empreendedoras.

Nesta pesquisa foi analisada duas dimensões:

Dimensão da participação familiar e influência de terceiros no desenvolvimento do empreendedorismo; 
Dimensão intenção/pretensão em empreender dos estudantes.

Após a aplicação do instrumento de análise, foi realizada a categorização dos dados para que fosse possível a classificação da pontuação segundo o questionário que utilizou uma escala Likert com perguntas de peso mínimo 1.00 e ao máximo 7.00.

O conjunto de questões sobre dimensão intenção/pretensão em empreender dos estudantes foi composto por 7 questões que analisam a intenção empreendedora do aluno, tendo como alternativas, "Discordo totalmente" a "Concordo totalmente".

Já o Conjunto questões que analisaram a dimensão da participação familiar foi composto por 11 questões de múltipla escolha partindo da alternativa "Discordo totalmente" a "Concordo totalmente".

Desse modo, é possível avaliar se as diferenças entre os níveis médios dos grupos captados pela survey são significativas entre os grupos e dentro de cada grupo (ROCHA; FREITAS, 2014). Por haver pequenas adaptações do GUESSS a este experimento, foi realizada uma análise fatorial e de variância multivariada (análise de fatores ortogonais com rotação Varimax), já que o uso destes métodos facilita a aglutinação dos fatores por similaridade (HAIR et al., 2006). Para todas as análises estatísticas de interesse desta pesquisa, foi considerado o nível de significância de $5 \%$.

Em razão de critérios éticos, precedendo ao início do questionário, foi inserido um Termo de Consentimento Livre e Esclarecido (TCLE), composto por esclarecimentos sobre a pesquisa, além da solicitação de autorização para o uso dos dados, e imagem que seja necessária ao desenvolvimento do experimento.

O questionário aplicado nesta pesquisa atende aos termos das Resoluções n. 466 de 12 de dezembro de 2012 do Conselho Nacional de Saúde (BRASIL, 2012), o qual por se tratar de survey com seres humanos foi submetido ao Comitê de Ética em Pesquisa Envolvendo Seres Humanos (CEP) e a Comissão Nacional de Ética em Pesquisa (CONEP) por meio da plataforma Brasil Saúde sendo APROVADO sob o número do Certificado de Apresentação para Apreciação Ética AAE: 23853219.4.0000.5546.

Os dados foram tratados, inicialmente, por uma análise de distribuição por meio da equação de Kolmogorov-Sminov ( $p>0,05$ ). Para o processamento dos dados foi utilizado o Software IBM SPSS (Statistical Package for the Social Sciences) (INTERNATIONAL BUSINESS MACHINES CORPORATION, 2017). 


\section{Resultados e discussão}

Visto que este programa se comporta como uma fase de pré-aceleração, este trabalho descreve os resultados de duas dimensões que influenciam na resposta da educação em empreendedorismo: a dimensão da Participação Familiar e Influência de Terceiros no Desenvolvimento do Empreendedorismo e a dimensão da intenção/pretensão em empreender dos estudantes.

\section{Dimensão e Intenção em Empreender dos Estudantes}

A dimensão da intenção empreendedora tem como base a Teoria da Ação Planificada (TAP), que é amplamente utilizada para prever diferentes tipos de intensões comportamentais em diferentes áreas de estudo (ROS; GOUVEIA, 2001; OLIVEIRA; MELO; MUYLDER, 2016). Por meio da análise desta dimensão, é possível compreender e predizer não só a partir de fatores psicológicos, como vontade e segurança, mas também fatores sociais, como a interação indivíduo e sociedade (KRUEGER; REILLY; CARSRUD, 2000). Assim, por meio desta dimensão é possível observar o quão um modelo de ensino pode influenciar positivamente ou negativamente os participantes.

É possível observar no Histograma (Figura 1) que ao participar de um programa educacional que promova atividades cadenciadas para o empreendedorismo, os alunos modificaram positivamente a sua intenção em empreender, passando de "Não sei responder" e "Concordo em partes" para "Concordo em partes" e "Concordo completamente". Demostrando que a aplicação de ações motivacionais e processos educacionais com metodologias ativas com incentivo ao empreendedorismo pode ser uma efetiva ferramenta para a melhoria da intenção em empreender (FAYOLLE; LINAN; MORIANO, 2014). É possível observar também que as respostas "Discordo completamente" e "Discordo em partes" se anularam à medida que o programa se desenvolveu, corroborando a afirmação anteriormente dita, que o programa influenciou positivamente os alunos participantes. 
Figura 1 - Histograma da dimensão da intenção em empreender por momento da pesquisa

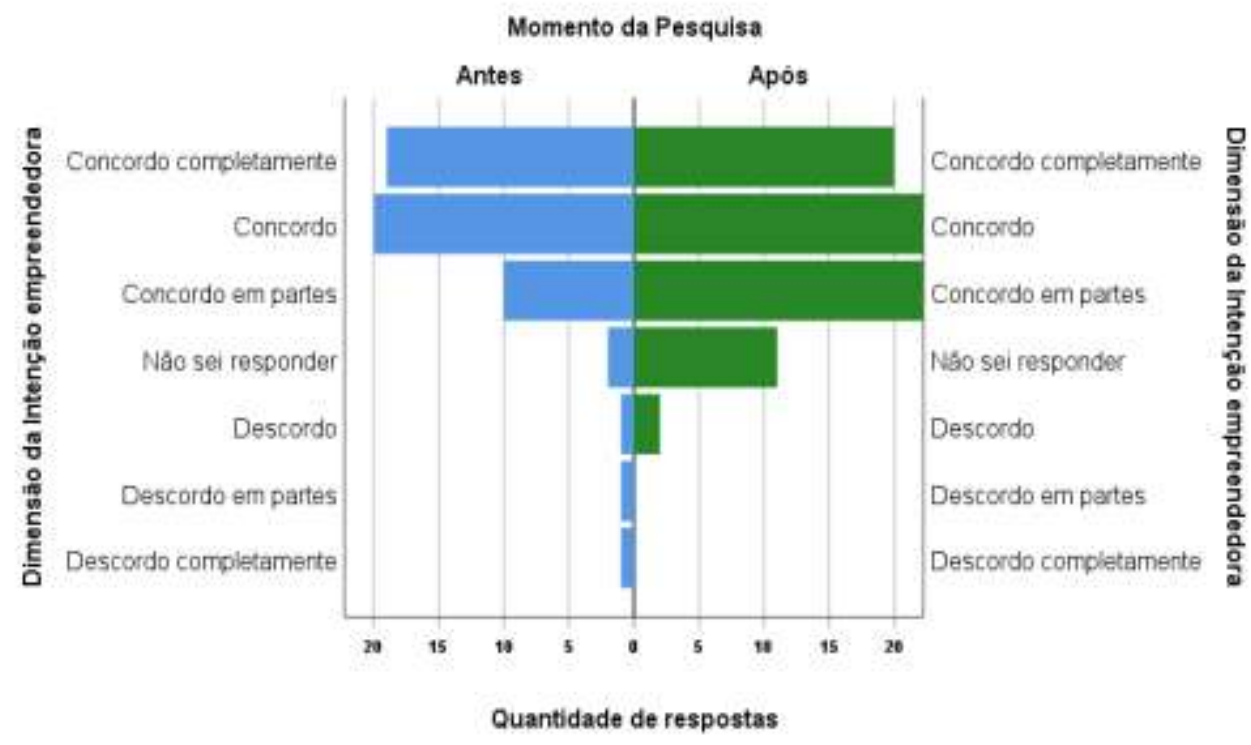

Fonte: Os autores (2020).

Quando observado o gráfico boxplot sobre a intenção empreendedora separados por cursos (Figura 2), o curso de Engenharia Agrícola demonstrou mobilidade positiva no $2^{\circ}$ e $3^{\circ}$ quartis saindo da afirmação "Concordo em partes”(5.00) para a afirmação "Concordo completamente" (7.00), assim como uma redução na dispersão na frequência das respostas.

Para o curso de engenharia Agronômica não houve mudança no $2^{\circ}$ quartil, no entanto foi observado que a dispersão dos resultados aumentou à medida que o programa evoluiu, demostrando que mesmo não havendo mobilidade do segundo quartil, o quarto quartil aumentou significativamente os valores, um provável motivo foi a melhoria da intenção em empreender posteriormente ao programa. Foi observado apenas um outlier, o participante 116.

O curso de Engenharia de pesca apresentou uma ligeira redução dos resultados, um provável fator foi a pouca participação dos alunos deste curso no programa Empreenda Agro Sustentável, reduzindo assim o grau de liberdade dos dados obtidos.

O curso de Zootecnia apresentou uma diferença positiva quando observados os valores localizados no $2^{\circ}$ quartil, no momento anterior ao programa a frequência das afirmações estavam entre o "Concordo em partes" (5.00) e "Concordo" (6.00), passando a estar localizado entre a afirmação "Concordo" (6.00) e "Concordo plenamente" (7.00). Houve uma redução da dispersão dos dados observados após o programa, destacando apenas um outlier, o participante 131. Já nos demais cursos que participaram da pesquisa, foi observada uma mobilidade positiva do $2^{\circ}$ quartil (mediana), saindo de "Concordo em partes" (5.00) para "Concordo completamente" (7.00). 
Figura 2 - Boxplot com Resultado da dimensão da intenção empreendedora por curso

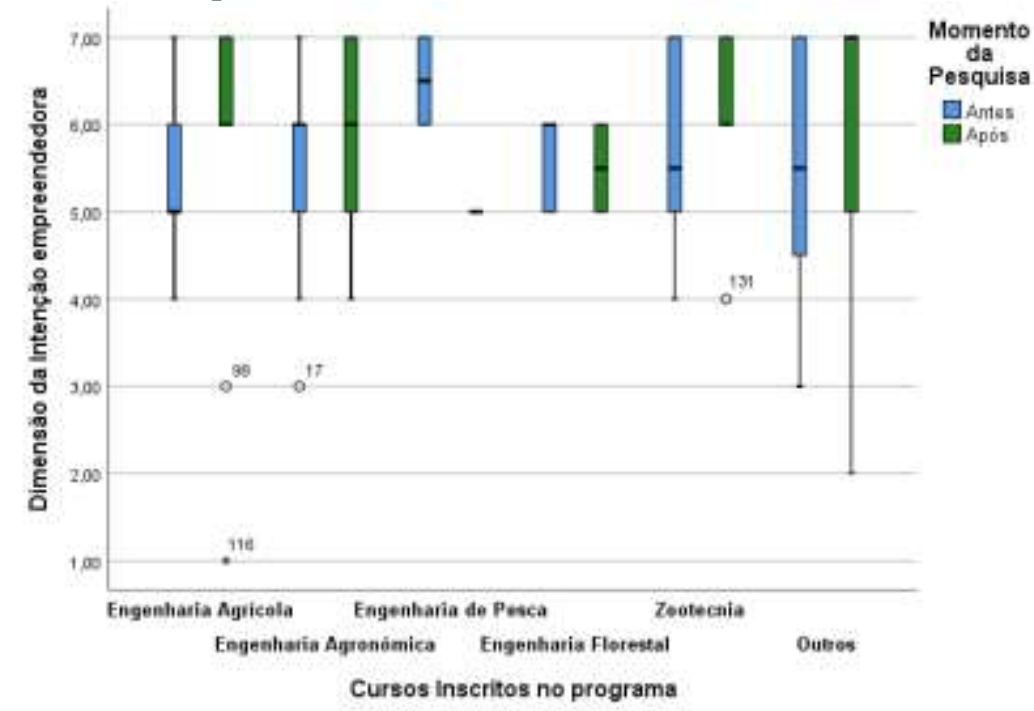

Fonte: Os autores (2020).

Observando as questões relacionadas com as satisfações pessoais e profissionais dos discentes (Tabela 1), é possível verificar que as afirmações: "Ser empreendedor me traria grande satisfação" e "Uma carreira de empreendedor é atrativa para mim" apesentaram mudanças positivas no questionário analisado. Tais questões relacionadas à intenção empreendedora demostram também que a participação constante em métodos educacionais que promovam o desenvolvimento da intenção empreendedora e autoeficácia nos participantes, interfere positivamente na autoconfiança e melhoria na satisfação profissional e pessoal, já que ambas estão associadas (NASSAR JUNIOR et al., 2016).

Estes fatores (satisfação pessoal e profissional) são de suma importância ao profissional que busca iniciar um novo negócio ou trabalhar com inovação, pois os fracassos em determinados projetos ao longo de sua carreira podem ser uma constante, e saber lidar com estes entraves deve ser uma habilidade adquirida ao longo do tempo (EDELMAN et al., 2016). 
Tabela 1 - Teste de amostras independentes para as questões relacionadas à intenção em empreender por momento do programa

\begin{tabular}{|c|c|c|c|c|}
\hline Questão & Momento da pesquisa & $\begin{array}{l}\text { Posto } \\
\text { Médio }\end{array}$ & Mediana & P-valor 0,05 \\
\hline \multirow{2}{*}{$\begin{array}{l}\text { Para mim, ser um empreendedor implica em } \\
\text { mais vantagens do que desvantagens }\end{array}$} & Antes & 64,43 & 6 & \multirow{2}{*}{0,082} \\
\hline & Após & 76,03 & 6 & \\
\hline \multirow{2}{*}{$\begin{array}{l}\text { Uma carreira como empreendedor é atrativa } \\
\text { para mim }\end{array}$} & Antes & 64,71 & 6 & \multirow{2}{*}{0,144} \\
\hline & Após & 74,26 & 7 & \\
\hline \multirow{2}{*}{$\begin{array}{l}\text { Se tivesse a oportunidade e os recursos, eu } \\
\text { me tornaria um empreendedor }\end{array}$} & Antes & 59,94 & 7 & \multirow{2}{*}{0,032} \\
\hline & Após & 72,91 & 7 & \\
\hline \multirow{2}{*}{$\begin{array}{l}\text { Ser um empreendedor traria grande satisfa- } \\
\text { ção para mim }\end{array}$} & Antes & 63,86 & 6 & \multirow{2}{*}{0,046} \\
\hline & Após & 76,90 & 7 & \\
\hline \multirow{2}{*}{ Pra mim sem empresa não é autônomo } & Antes & 58,89 & 4 & \multirow{2}{*}{0,016} \\
\hline & Após & 74,81 & 5 & \\
\hline \multirow{2}{*}{$\begin{array}{l}\text { Por gentileza, indique se você tem pensado e } \\
\text { o quão seriamente tem pensado em criar seu } \\
\text { próprio negócio }\end{array}$} & Antes & 64,34 & 6 & \multirow{2}{*}{0,076} \\
\hline & Após & 76,17 & 6 & \\
\hline \multirow{2}{*}{$\begin{array}{l}\text { Eu já sou meu próprio patrão na empresa que } \\
\text { eu fundei }\end{array}$} & Antes & 72,08 & 1 & \multirow{2}{*}{0,143} \\
\hline & Após & 63,06 & 1 & \\
\hline \multirow{2}{*}{$\begin{array}{l}\text { Tenho precisão consistente do que empreen- } \\
\text { der e datas para os passos da fundação }\end{array}$} & Antes & 65,86 & 3 & \multirow[t]{2}{*}{0,241} \\
\hline & Após & 73,83 & 4 & \\
\hline
\end{tabular}

Fonte: Os autores (2020).

O estudo observou que para a questão "Eu já sou patrão na empresa que criei", obteve-se desempenho negativo, provavelmente pela ocorrência de evasão dos alunos ao longo dos workshops realizados no programa, que foi demonstrado por defasagem nas respostas, de maneira que podemos inferir que permaneceram apenas os alunos que não são donos de negócios.

Considerando o valor de 1227 alunos como população do universo pesquisado, 95\% (Z =1.96) para o valor médio que foi aceito para alcançar o nível de confiança desejado segundo a distribuição de Gauss, admitindo também a margem de erro máximo de $0.5 \%$ foram abertas 300 vagas que foram preenchidas 118, e ficando até o final do experimento 60 alunos. Desta forma, por consequência da evasão, esta pesquisa apresentou uma margem de erro de $8.57 \%$ quando observado a população no início do experimento e 93 alunos que representam uma margem de erro de $9.8 \%$.

A evasão em projetos educacionais muito antes do início, segundo Ribeiro (2005), pode ser respondida pela falta da cultura de promoção dos modelos educacionais práticos dentro da universidade, assim como projetos que mostrem aos alunos como alavancar seus projetos de vida profissional. Pode contribuir também para a evasão e o interesse dos alunos, a falta de perspectiva de mudança de vida e o distanciamento da cultura empreendedora. 
A afirmação "Se tivesse oportunidade e os recursos en me tornaria um empreendedor", apresentou diferença significativa positiva. A Intenção Empreendedora antecede o passo de criação do negócio, assim esta questão traz como certo que as restrições financeiras, falta de informação e a insegurança em capital específico podem interferir na abertura de novos negócios mesmo que esteja presente a Intenção Empreendedora (AUGUSTE; BRICKER, 2016).

Quando observado o posto médio da questão "Porgentileza, indique se você tem pensado e o quão seriamente tem pensado em criar seu próprio negócio” houve uma ligeira mudança positiva que foi de 64,34 para 76,17. Esta questão está ligada ao fato de que a vivência constante do aluno em um ambiente que proporcione conteúdos e conhecimentos relacionados ao empreendedorismo e inovação, pode influenciar este a pensar e planejar o desenvolvimento de novos negócios, demostrando uma real necessidade do surgimento de programas que incentivem ao desenvolvimento de novos negócios, cabendo aos locais de ensino proporcionar ao máximo essas vivências (DAMANPOUR; SCHNEIDER, 2006).

A intenção em gerar um novo negócio tal qual a aqui discutida, é considerado um dos melhores preditores do empreendedorismo bem sucedido (AJZEN, 1987; GARCIA-RODRIGUEZ et al., 2017; KRUEGER; BRAZEAL, 2018), e é capaz de modificar positivamente não somente o novo empreendedor, mas também seu meio social como um todo, gerando emprego e renda direta e indiretamente (GONZAGA, 2017).

Avaliação da Dimensão da Participação Familiar e Influência de Terceiros no Desenvolvimento do Empreendedorismo

É de suma importância a análise sobre a influência da família e contatos próximos ao estudante propenso a empreender, já que a família é uma importante fonte de networking para novos negócios (KUPP; SCHMITZ; HABEL, 2019; RAZA; MUFFATTO; SAEED, 2019; SOTO; DELGADO, 2019), desde o financiamento no estágio inicial do negócio (EDELMAN et al., 2016) até os cuidados no âmbito familiar (MELIOU, 2020; PUZI; ISMAIL; JAAFAR, 2020).

Pesquisas atuais sugerem que o potencial transformacional dos cuidados familiares pode influenciar positivamente para a viabilidade dos negócios e posiciona a família em um ponto-chave para o surgimento de novos negócios (GEORGESCU; HERMAN, 2020; JENA, 2020; PORFÍRIO; FELÍCIO; CARRILHO, 2020).

No geral a participação no programa não influenciou positivamente a dimensão da participação familiar dos alunos vinculados ao programa Figura 3. 
Figura 3 - Contagem geral por momento da pesquisa sobre a participação familiar e influência de terceiros

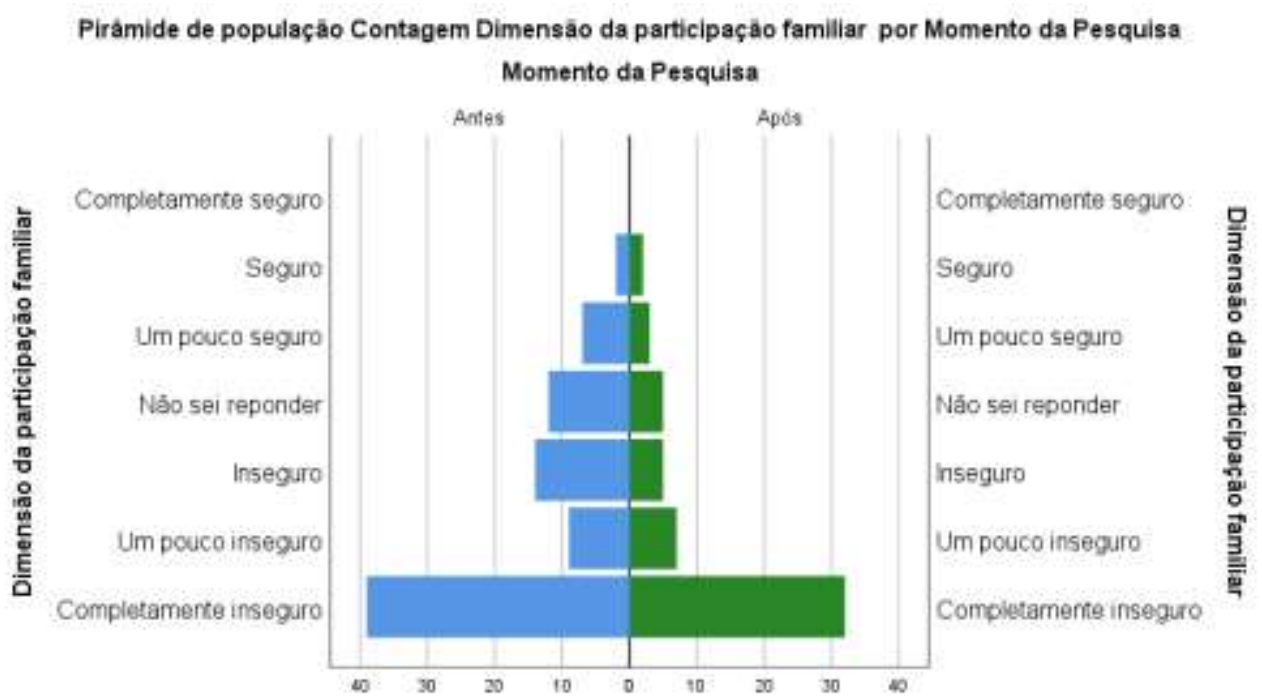

Fonte: Os autores (2020).

Quando observado o gráfico em boxplot sobre a Participação familiar separados por cursos (Figura 4), o curso de Engenharia de Pesca demonstrou maior mobilidade quando observado os resultados referentes a participação familiar, porem não ouve diferença positiva pois, os resultados saíram de "Inseguro" (3.00) para "Não sei responder" (4.00).

Para o curso de engenharia Agronômica, Engenharia Florestal e Zootecnia apresentaram retração, onde os alunos de Engenharia Agronômica respondendo que se sentiam inicialmente " $U m$ pouco seguro" (2.00) e ao final do programa responderam que estavam "Completamente Inseguro" (1.00), quando observadas as respostas dos alunos de Engenharia Florestal é possível observar que estes responderam no começo do programa que se sentiam "Inseguro" (3.00) para resultados entre "Inseguro" (3.00) e "Um pouco Inseguro" (2.00), corroborando com os resultados dos demais cursos.

Para o curso de Zootecnia foi observada uma queda significativa no escore das respostas saindo de "Inseguro" (3.00) para "Completamente Inseguro" (1.00), um provável fator foi a evasão de alunos deste curso que inicialmente contava com 21 para 16 alunos, podendo ter influenciado no resultado do grupo avaliado. A evasão em projetos promovidos pelos centros de ensino é um fenômeno social complexo, definido como interrupção danosa no ciclo de estudos (BAGGIO; BAGGIO, 2015).

Este problema vem preocupando as instituições de ensino em geral, sejam públicas ou particulares, pois a saída de alunos provoca graves consequências institucionais, já que toda atividade pedagógica deve ter um planejamento prévio e estruturado para o atendimento do corpo discente objeto dos projetos (FIGUEIREDO et al., 2017). 
Este fato pode ter ocorrido também pela falta da cultura de promoção dos modelos educacionais práticos dentro da universidade, assim como projetos que mostrem aos alunos como alavancar seus projetos de vida profissional (NOBRE et al., 2016), ocorrendo em projetos educacionais muito antes de seu início (RIBEIRO, 2005). Outros fatores podem contribuir também para a evasão e o interesse dos alunos tais como: A falta de perspectiva de mudança de vida e o distanciamento da cultura empreendedora.

O curso de Engenharia Agrícola se manteve no escore inicial “Completamente Inseguro" (1.00).

Figura 4 - Boxplot da percepção sobre a participação familiar e influência de terceiros por momento da pesquisa

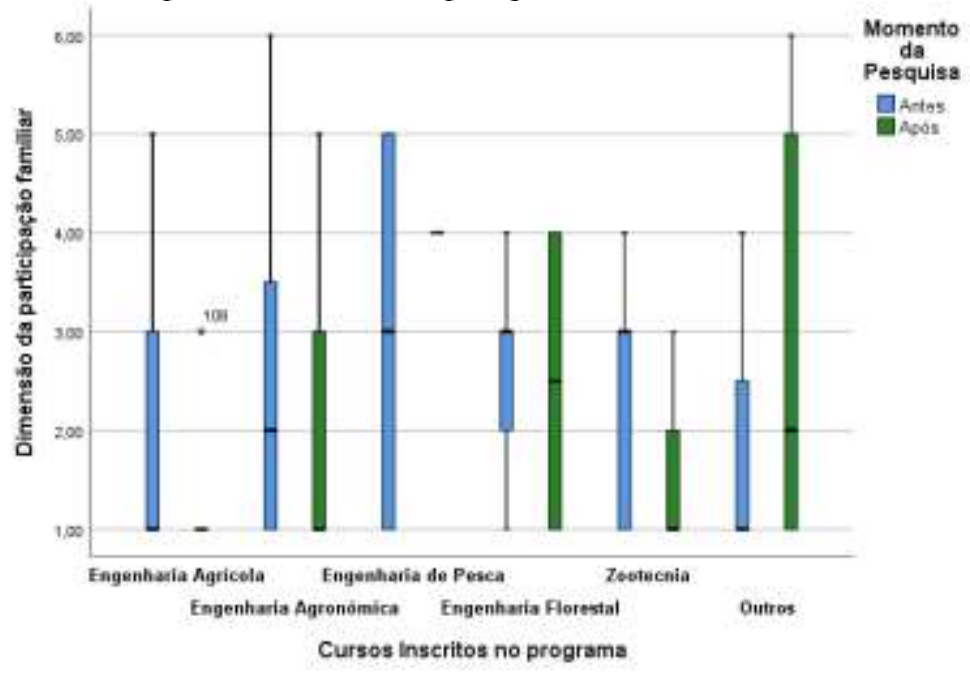

Fonte: Os Autores (2020).

Os dados apresentados demonstram que esta dimensão deve ser mais bem explorada em futuras pesquisas, visto que esta dimensão pode influenciar negativamente na escalabilidade do negócio planejado pelo novo empreendedor.

A família costuma desempenhar importantes funções de incubação no processo de criação de novos empreendimentos, uma vez que muitos negócios podem surgir do empreendedorismo transgeracional (RIBEIRO; RIBEIRO, 2015) ou da mobilização de recursos familiares, demonstrando a importância desta dimensão ser melhor estudada em futuros trabalhos.

Por outro lado, muitos profissionais não têm apoio familiar para desempenhar o papel de gestor de seu próprio negócio ficando este dependente de investimento externo viável e que seja capaz de alavancar um novo negócio (MENGUE; SCHMIDT; BOHNENBERGER, 2019), tais como investimento do setor público vindo de editais e programas e fundos de investimentos, aceleradores e incubadoras; Capital privado de investidores anjos e o Venture Capital (FONSECA; DOMINGUES, 2018; MARINHO, 2019). 


\section{Considerações finais}

Os estudantes participantes encontram maior segurança para o próximo passo que é o de aceleração de seus planos de negócios, conquistando autonomia, buscando novas oportunidades, como profissionais proativos com destaque no mercado de trabalho.

A participação familiar foi apontada como um fator pouco influenciável no desenvolvimento para novos negócios rurais desenvolvidos por programa de ensino ao empreendedorismo.

O capital financeiro foi apontado em unanimidade quando analisado os dados por curso como um importante fator impeditivo ao desenvolvimento do novo negócio.

A pesquisa aponta que investimentos financeiros fora o ceio familiar são essenciais para o desenvolvimento de novos negócios, de forma que as contribuições familiares deverá ser apenas como complementar o recurso financeiro do negócio.

\section{Referências}

AJZEN, I. Attitudes, traits, and actions: dispositional prediction of behavior in personality and social psychology. In: BERKOWITZ, L. (org.). Advances in Experimental Social Psychology. [S. l.]: Academic Press, 1987. v. 20. p. 1-63. Disponível em: http://www.sciencedirect.com/science/article/pii/S0065260108604116. Acesso em: 13 abr. 2020.

ANDRADE, J. dos S.; FERNANDES, S. A. de S. A importância da educação contextualizada para o desenvolvimento do semiárido. Revista NERA, Presidente Prudente, v. 19, n. 34, 157-178, 2016.

AUGUSTE, S.; BRICKER, A. What leads and what restricts entrepreneurship? Evidence from Argentina. [S. l.]: Mimeo, 2016.

BAGGIO, A. F.; BAGGIO, D. K. Empreendedorismo: conceitos e definições. Revista de Empreendedorismo, Inovação e Tecnologia, [s. l.], v. 1, n. 1, p. 25-38, jan. 2015.

BASTOS, P. de M. A.; MATTTOS, L. B. de; SANTOS, G. C. Determinantes da pobreza no meio rural brasileiro. Revista de Estudos Sociais, [s. l.], v. 20, n. 41, p. 4-30, 2018.

BRASIL. Ministério da Indústria, Comércio Exterior e Serviços. Comércio Exterior e Serviços. Comex Stat: exportação agrícola do Brasil. Banco de dados. Brasília, [2020]. Disponível em: http://comexstat.mdic.gov.br/pt/geral. Acesso em: 16 nov. 2020.

BRASIL. Ministério da Saúde. Conselho Nacional de Saúde. Resolução n 466, de 12 de dezembro de 2012. Brasília, DF, 2012.

COSTA, P. da et al. Educação e empreendedorismo para o desenvolvimento rural sustentável. In: COSTA, J. R. da et al. (ed.). Educação de qualidade: contribuições da Embrapa. Brasília, DF: Embrapa, 2018. p. 43-62. 
DAMANPOUR, F.; SCHNEIDER, M. Phases of the adoption of innovation in organizations: effects of environment, organization and Top Managers1. British Journal of Management, Chinchester, v. 17, n. 3 , p. $215-236$, set. 2006.

DORNELAS, J. C. A. Empreendedorismo Corporativo: como ser empreendedor, inovar e se diferenciar em organizações estabelecidas. 3. ed. São Paulo: LTC, 2015. v. 1.

EDELMAN, L. F. et al. The impact of family support on young entrepreneurs' start-up activities. Journal of Business Venturing, New York, v. 31, n. 4, p. 428-448, jul. 2016.

FAUSTINO, M.; AMADOR, F. O conceito de "sustentabilidade": migração e mudanças de significados no âmbito educativo. Indagatio Didactica, [s. l.], v. 8, n. 1, p. 2021-2033, jan. 2016.

FAYOLLE, A.; LINAN, F.; MORIANO, J. A. Beyond entrepreneurial intentions: values and motivations in entrepreneurship. International Entrepreneurship and Management Journal, [s. l.], v. 10, n. 4, p. 679-689, dez. 2014.

FERREIRA, A. da S. M. et al. Preditores individuais e contextuais da intenção empreendedora entre universitários: revisão de literatura. Cadernos EBAPE.BR, [s. l.], v. 15, n. 2, p. 292-308, jun. 2017.

FIGUEIREDO, N. G. da S. et al. Educação Profissional e evasão escolar em contexto: motivos e reflexões. Ensaio: Avaliação e Políticas Públicas em Educação, Rio de Janeiro, v. 25, n. 95, p. 356392, abr. 2017.

FONSECA, V. C.; DOMINGUES, J. O. Financiamento de startups: aspectos econômicos dos investimentos de alto risco e mecanismos jurídicos de controle. Revista de Direito Econômico e Socioambiental, Curitiba, v. 9, n. 1, p. 319-354, 2018.

FREIRE, P. Pedagogia do oprimido. 17 ed. Rio de Janeiro: Paz e Terra, 1987.

FREITAS, A. F. de; FREITAS, A. F. de; DIAS, M. M. Mudanças conceituais do desenvolvimento rural e suas influências nas políticas públicas. Revista de Administração Pública, Rio de Janeiro, v. 46, n. 6, p. 1575-1597, dez. 2012.

GARCIA-RODRIGUEZ, F. J. et al. Entrepreneurial process in peripheral regions: the role of motivation and culture. European Planning Studies, Abingdon, v. 25, n. 11, p. 2037-2056, nov. 2017.

GEORGESCU, M.-A.; HERMAN, E. The impact of the family background on students' entrepreneurial intentions: an empirical analysis. Sustainability, Switzerland, v. 12, n. 11, 2020.

GONZAGA, S. K. Infraestrutura culinária sob a ótica da administração: como a abordagem sistêmica pode auxiliar na geração de valor em novos negócios. [S. l.: s. n.], 2017.

HAIR, J. F. et al. Multivariate data analysis. Upper Saddle River, NJ: Pearson Prentice Hall, 2006. v. 6.

IBGE. Coordenação de População e Indicadores Sociais. Sintese de indicadores sociais: uma análise das condições de vida da população brasileira em 2020. Rio de Janeiro, 2020. 
INTERNATIONAL BUSINESS MACHINES CORPORATION. IBM SPSS Statistics for Macintosh, Version 25.0. Armonk, 2017.

JENA, R. K. Measuring the impact of business management Student's attitude towards entrepreneurship education on entrepreneurial intention: a case study. Computers in Human Behavior, [s. l.], v. 107, jun. 2020. DOI: https://doi.org/10.1016/j.chb.2020.106275.

KAGEYAMA, A. O novo padrão agrícola brasileiro: do complexo rural aos complexos agroindustriais. In: AGRICULTURA e políticas públicas. Brasília, [s. n.], 1990. p. 113-223.

KRUEGER, N. F.; BRAZEAL, D. V. Potencial empreendedor e empreendedores em potencial (Entrepreneurial Potential and Potential Entrepreneurs). Revista de Empreendedorismo e Gestão de Pequenas Empresas, [s. l.], v. 7, n. 2, p. 201-226, 2018.

KRUEGER, N. F.; REILLY, M. D.; CARSRUD, A. L. Competing models of entrepreneurial intentions. Journal of Business Venturing, New York, v. 15, n. 5, p. 411-432, set. 2000.

KUPP, M.; SCHMITZ, B.; HABEL, J. When do family firms consider issuing external equity? Understanding the contingent role of families' need for control. Journal of Family Business Management, [s. l.], v. 9, n. 9, set. 2019. Disponível em: https:/ /www-emerald.ez20.periodicos.capes.gov.br/insight/content/doi/10.1108/JFBM-08-2018-0021/full/html. Acesso em: 13 abr. 2020.

LAZZARESCHI, N. Novas competências profissionais e empregabilidade no limiar do século XXI. Estudos de Sociologia, Recife, v. 1, n. 22, p. 245-290, 2016.

LEITE, E. D.; DIAS, C. N. Aprendizagem empreendedora para o desenvolvimento de regiões brasileiras: o fomento de competências na formação acadêmica do Instituto Federal de Brasília. Negócios em Proję̧ão, [s. l.], v. 6, n. 1, p. 204-220, 2015.

LOPES, R. M. A. Educação empreendedora: conceitos, modelos e práticas. [S. l.]: Elsevier, 2010.

MARINHO, G. M. Startups: conceito, natureza jurídica e os contratos de investimento. 2019. Dissertação (Mestrado em Direito das Empresas e do Trabalho) - Instituto Universitário de Lisboa, Lisboa, 2019.

MELIOU, E. Family as a eudaimonic bubble: Women entrepreneurs mobilizing resources of care during persistent financial crisis and austerity. Gender, Work \& Organization, Oxford, v. 27, n. 2, p. 218-235, mar. 2020.

MENGUE, T. H. S.; SCHMIDT, S.; BOHNENBERGER, M. C. Contribuições do investimento anjo para o desenvolvimento de startups na região metropolitana de Porto Alegre. Revista Gestão e Desenvolvimento, [s. l.], v. 16, n. 1, p. 71-98, fev. 2019.

NASSAR JUNIOR, A. P. et al. Fatores associados à satisfação profissional e pessoal em intensivistas adultos brasileiros. Revista Brasileira de Terapia Intensiva, São Paulo, v. 28, n. 2, p. 107-113, jun. 2016.

NITAHARA, A. Informalidade no mercado de trabalho é recorde. Rio de Janeiro: Agência Brasil, 31 out. 2019. Disponível em: http://agenciabrasilebc.com.br/economia/noticia/2019-10/informalidade-no-mercado-de-trabalho-e-recorde-aponta-ibge. Acesso em: 7 jan. 2020. 
NOBRE, F. et al. A amostragem na pesquisa de natureza científica em um campo multiparadigmático: peculiaridades do método qualitativo. CIAIQ, [s. l.], v. 3, p. 157-166, jul. 2016. Disponível em: https:// proceedings.ciaiq.org/index.php/ciaiq2016/article/view/938. Acesso em: 25 set. 2020.

OLIVEIRA, A. G. M. de; MELO, M. C. de O. L.; MUYLDER, C. F. D. Educação Empreendedora: o desenvolvimento do empreendedorismo e inovação social em instituições de ensino superior. Revista Administração em Diálogo, [s. l.], v. 18, n. 1, p. 29-56, jan. 2016.

PIETROVSKI, E. F. et al. Análise do potencial empreendedor em alunos do ensino superior: aplicação da teoria à prática. Innovar: Revista de Ciencias Administrativas y Sociales, [s. l.], v. 29, n. 71, p. 25-42, 2019.

PIRAUX, M.; CANIELLO, M. Reflexões retrospectivas e prospectivas sobre a governança territorial para o desenvolvimento rural no Brasil. Raizzes: Revista de Ciências Sociais e Econômicas, Campina Grande, v. 39, n. 2, p. 359-379, 2019. Disponível em: https://agritrop.cirad.fr/595518/. Acesso em: 20 jul. 2020.

PORFÍRIO, J. A.; FELÍCIO, J. A.; CARRILHO, T. Family business succession: analysis of the drivers of success based on entrepreneurship theory. Journal of Business Research, Athens, v. 115, p. 250-257, 2020.

PUZI, M. A. M.; ISMAIL, H. N.; JAAFAR, S. M. R. S. Transgenerational entrepreneurship and survivability in rural economy. IOP Conference Series: Earth and Environmental Science, [s. l.], v. 447, p. 012070, mar. 2020.

RAZA, A.; MUFFATTO, M.; SAEED, S. The influence of formal institutions on the relationship between entrepreneurial readiness and entrepreneurial behaviour. Journal of Small Business and Enterprise Development, [s. l.], v. 26, n. 6, fev. 2019. Disponível em: https://www-emerald.ez20.periodicos.capes.gov.br/insight/content/doi/10.1108/JSBED-01-2018-0014/full/html. Acesso em: 13 abr. 2020.

RIBEIRO, M. A. O projeto profissional familiar como determinante da evasão universitária-um estudo preliminar. Revista Brasileira de Orientação Profissional, São Paulo, v. 6, n. 2, p. 55-70, 2005.

RIBEIRO, M. A. R.; RIBEIRO, M. A. R. Riqueza e endividamento na economia de plantation açucareira e cafeeira: a família Teixeira Vilela-Teixeira Nogueira, Campinas, São Paulo, século XIX. Estudos Econômicos, São Paulo, v. 45, n. 3, p. 527-565, set. 2015.

ROCHA, E. L. de C.; FREITAS, A. A. F. Avaliação do Ensino de Empreendedorismo entre Estudantes Universitários por meio do Perfil Empreendedor. Revista de Administração Contemporânea, Rio de Janeiro, v. 18, n. 4, p. 465-486, ago. 2014.

RODRIGUES, I. L. et al. Intenção empreendedora em estudantes de administração: um estudo com estudantes da Universidade Federal do Ceará. REMIPE - Revista de Micro e Pequenas Empresas e Empreendedorismo da Fatec Osasco, Osasco, v. 5, n. 1, p. 65-84, 30 jan. 2019.

ROS, M.; GOUVEIA, V. V. Psicología social de los valores humanos. Desarrollos teóricos, metodológicos y aplicados. Madrid: Editorial Biblioteca Nueva, 2001. 
SCHAEFER, R.; MINELLO, Í. F. A formação de novos empreendedores: natureza da aprendizagem e educação empreendedora. Revista da Micro e Pequena Empresa, Campo Limpo Paulista, v. 11, n. 3, p. 2-20, 21 dez. 2017. DOI: http://dx.doi.org/10.21714/19-82-25372017v11n3p220.

SILVA, E. G. da. Mudança estrutural e crescimento econômico: uma questão esquecida. Sociologia: Revista da Faculdade de Letras da Universidade do Porto, Porto, v. 14, 31 maio 2017. Disponível em: https://pentaho.letras.up.pt/index.php/Sociologia/article/view/2463. Acesso em: 18 jan. 2020.

SOTO, J. D.; DELGADO, P. L. Does Family and Lone Founder Involvement Lead to Similar Indebtedness? Journal of Small Business Management, Morgantown, v. 57, n. 4, p. 1531-1558, out. 2019.

SOUZA, D. L. et al. Empreendedorismo e desenvolvimento local: uma análise do programa microempreendedor individual em Minas Gerais, Brasil. Desenvolvimento em Questão, Ijuí, v. 14, n. 37, p. 262-292, 2016.

UNIVERSIDADE FEDERAL DE SERGIPE. UFS em Número 2017. Sergipe, 2018.

VICENTINI, D. H.; PIZZUTTI, J. H.; CARVALHO, M. R. de. A influência da liderança em tempos de crise. Revista Cientifica, [s. l.], v. 1, n. 1, nov. 2018. Disponível em: http://revistas.unilago.edu.br/index.php/revista-cientifica/article/view/83. Acesso em: 16 nov. 2020.

VIEIRA, S. C.; BERNARDO, C. H. C.; LOURENZANI, A. E. B. S. Política Pública de ATER para o desenvolvimento rural sustentável na Agricultura Familiar. Revista Eletrônica Competências Digitais para Agricultura Familiar, Tupã, v. 1, n. 1, p. 1-22, nov. 2015. 